\title{
Development of an H-TDMA for long-term unattended measurement of the hygroscopic properties of atmospheric aerosol particles
}

\author{
E. Nilsson, E. Swietlicki, S. Sjogren, J. Löndahl, M. Nyman, and B. Svenningsson \\ Div. of Nuclear Physics, Dept. of Physics, Lund University, P.O. Box 118, 22100, Lund, Sweden
}

Received: 11 March 2009 - Published in Atmos. Meas. Tech. Discuss.: 15 April 2009

Revised: 23 June 2009 - Accepted: 24 June 2009 - Published: 30 June 2009

\begin{abstract}
A new hygroscopic tandem differential mobility analyzer (H-TDMA) has been constructed at Lund University within the frameworks of the EU FP6 Infrastructure Project EUSAAR (www.eusaar.org). The aim of this coordinated H-TDMA development is to design and evaluate a new generation of H-TDMAs that are capable of conducting long term measurements of the hygroscopic growth and state of mixing of sub-micrometer atmospheric aerosol particles at the EUSAAR aerosol super-sites across Europe. The HTDMA constructed for this project has been validated with respect to hygroscopic growth factor, stability of relative humidity (RH), temperature stability and its ability to operate unattended for longer periods of time. When measuring growth factors of ammonium sulphate, the new H-TDMA system was found to measure within a growth factor deviation of \pm 0.05 compared to previously recorded data by Tang et al. (1994). The long term RH of the system has been found stable at $90.0 \%$ with a standard deviation of $\pm 0.23 \%$ and an average temperature variability of the second DMA less than $\pm 0.1 \mathrm{~K}$. Daily automated ammonium sulphate measurements have validated the ambient measurements. The instrument is operated at the EMEP/EUSAAR background station Vavihill in the southern part of Sweden.
\end{abstract}

\section{Introduction}

The chemical properties of the atmospheric aerosol are important for the life cycle of the particles, for local visibility and health effects as well as for the direct and indirect effects of aerosols on climate (Kaufmann et al., 2002). Water vapour in the atmosphere interacts with aerosol particles, which take up water according to changes in the relative humidity of the

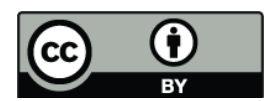

Correspondence to: E. Nilsson (erik.nilsson@nuclear.lu.se) surrounding air. The hygroscopicity of the particles can be described according to their hygroscopic growth factor, GF, which is defined as

$\mathrm{GF}=\frac{d(\mathrm{RH})}{d_{0}}$

where $d_{0}$ is the mobility diameter of the dry particle, and $d(\mathrm{RH})$ is the diameter of the humidified particle. At water vapour subsaturation, and at low supersaturation (SS) ratios, the particles take up or evaporate water vapour until their water activity is in equilibrium with its surroundings, which affects the light scattering properties of the particles. However, at a certain SS ratio, known as the critical SS, the particles start to grow unrestrained, as long as there is water vapour available, and become cloud droplets. The critical SS value is dependent on the chemical composition and the size of the particle and of utmost importance to the characteristics of the cloud formed. Hygroscopic measurements of atmospheric aerosol particles have been carried out since the 1980s with Rader and McMurry (1986) as pioneering in using the measurement principle of two DMAs with a humidification system in between on an atmospheric aerosol. This measurement instrument is commonly known as the Hygroscopic Tandem Differential Mobility Analyzer (H-TDMA) (Swietlicki et al., 2008). H-TDMA measurements of aerosol particles have until now been limited to short field campaigns of maximum a few months in duration, since these instruments typically require frequent maintenance and have therefore not been suitable for unattended long-term operation, but recently, initiated by the EU FP6 Infrastructure Project EUSAAR (www.eusaar.org), attempts have been made to construct instruments designed for long term measurements. Duplissy et al. (2008) made an intercomparison of $6 \mathrm{H}$-TDMA systems within the EUSAAR project, and based on this study, recommendations were set for how to construct an instrument especially suited for long term measurements.

Published by Copernicus Publications on behalf of the European Geosciences Union. 


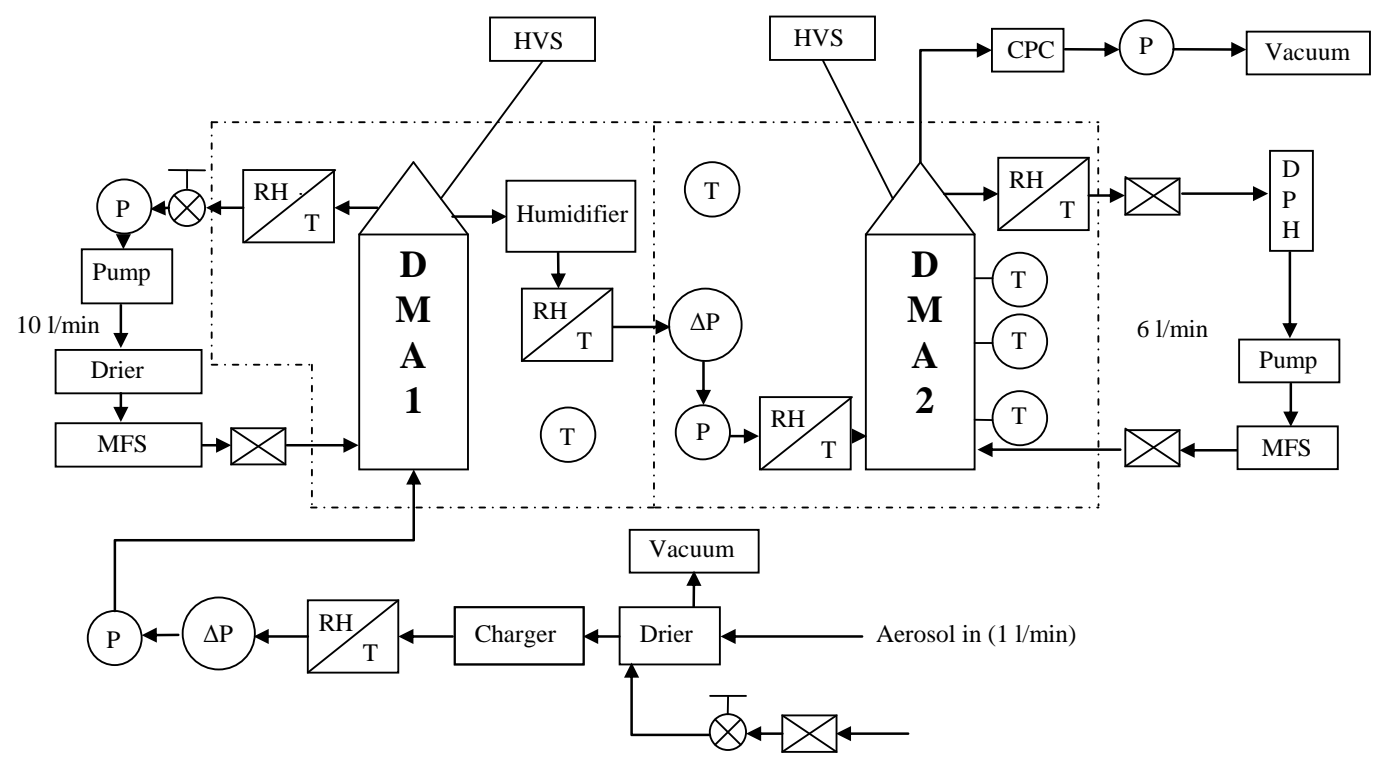

\begin{tabular}{llll}
\multicolumn{2}{l}{ Abbreviations and symbols: } \\
$\mathrm{P}$ & Pressure sensor & DPH & Dew point hygrometer \\
$\Delta \mathrm{P}$ & Differential pressure sensor \\
$\mathrm{MFS}$ & Mass flow sensor & & Needle valve \\
$\mathrm{RH}$ & $\mathrm{RH}$ sensor & &
\end{tabular}

Fig. 1. Schematics of the H-TDMA system.

We have constructed and tested an H-TDMA according to the recommendations given by EUSAAR. The instrument performance has been evaluated based on stability in temperature and relative humidity in the field and the ability of the instrument to reproduce literature values of hygroscopic growth, as well as its data coverage during the first 6 months of operation.

\section{Material and methods}

Tandem Differential Mobility Analyzers (TDMA:s) were first introduced by Liu et al. (1978) and fundamentally consists of three parts: 1) A DMA (in our case a Vienna type DMA, $28 \mathrm{~cm}$ long), selecting a quasi monodisperse aerosol, previously charged (in our case with a ${ }^{85} \mathrm{Kr}$ diffusion charger) based on the particles electrical mobility. 2) A conditioning unit, controlling e.g. the temperature or relative humidity of the aerosol particles. 3) A second DMA (in our case a Vienna type, $50 \mathrm{~cm}$ long), which together with a condensation particle counter (CPC) determines the size distribution of the conditioned, previously quasi monodisperse, aerosol. In order to enable stable long-term measurements with high time resolution, the H-TDMA developed in this work was constructed with closed loop systems for excess- sheath flows in both DMAs, continuously scanning DMA2 voltage, humidification only in the aerosol line, active temperature control of both DMAs, and a master-slave control system of the aerosol $\mathrm{RH}$, in order to keep the relative humidity $(\mathrm{RH})$ in the second DMA as close to the set point as possible during longer periods of time. The schematics of the set-up developed in this work are presented in Fig. 1.

There are three major advantages with using a closed loop flow: avoiding the problem of balancing the sheath and excess flows, simplifying the instrument construction and stabilising the RH. The balancing of the sheath and excess flow can be complicated in an open end system, as the volume flow is dependent on pressure, temperature and RH. To make an open end system work properly, all sensors in the sheath and excess air, as well as the mass flow controllers (MFCs) have to be calibrated on a regular basis and both vacuum and pressurised air has to be available for the H-TDMA system at all times. By using a closed loop system instead, the system is simplified. In this work, a membrane pump (Vacuubrand MD1) with a needle valve was used for the first DMA loop. For the second DMA a linear pump was used (Gardner Denver, 6025 DC). Since the water vapour in the second loop is recirculated, the net flows into the DMAs from sheath and excess are always 0 . In this way, the RH control becomes more stable, since fluctuations in the aerosol 
humidification is buffered in the volume of the second DMA and its loop. This is ideal for long term measurements at a stable RH value. However, for more intensive measurement campaigns were a more dynamic system is preferred, an open end system may be a better alternative. The sheath flow rates in the system were set to $101 / \mathrm{min}$ for DMA1 and $61 / \mathrm{min}$ for DMA2. The aerosol flow through the system was set to $1 \mathrm{l} / \mathrm{min}$, hence giving flow ratios of $10: 1$ and $6: 1$ respectively. A higher sheath to aerosol flow will give a higher size resolution of the system, but with the drawback of lower counting statistics and a narrower sizing interval, as higher flows need higher voltages for the selection of a particular electrical mobility, and the maximum voltage that can be used for a DMA is limited. In this work, a flow ratio of 6:1 was set in the second DMA to avoid electrical discharges in the humid air and to still be able to measure a GF of 2.2 for the largest dry size selected $(265 \mathrm{~nm})$.

Scanning voltage is preferable, since it eliminates the "dead time" that otherwise occur in between the different fixed voltages in a stepping system, when data recording has to be temporarily stopped during particle free flushing of the DMAs. However, too fast scanning will lead to problems in the inversion of the data, since there is a smearing effect in the CPC, caused by the mixing of particles inside the particle counter and this effect will be an increasing problem as scanning speed increases. This is not an issue for stepping systems, since the particles entering the CPC is not varying with time during the measurement.

There are many different approaches that can be used for humidification of aerosol and sheath air. Previously used systems include water-to-gas Gore-Tex ${ }^{\circledR}$ humdification (e.g. Zhou, 2001; Ehn et al., 2007), water-to-gas nafion membrane humidification (Hennig et al., 2005), gas-to-gas nafion humidification (Santarpia et al., 2004; Massling et al., 2005) or a controlled mixing of humid and dry air (Weingartner et al., 1999). In this work, water-to-gas Gore-Tex ${ }^{\circledR}$ humidification was used for the aerosol line. This system has proven robust in the past and was chosen because of its simplicity. The aerosol is led through a $5 \mathrm{~cm}$ long Gore-Tex ${ }^{\circledR}$ tube with an inner diameter of $6 \mathrm{~mm}$ with counter flow water purging on the outside of the membrane. The tube is placed vertically, with the purging water flowing upwards, to avoid air bubbles which can potentially disturb the RH control. This water is heated or cooled with two $25 \times 25 \mathrm{~mm}$ Peltier elements to obtain the desired RH, which can be set between $30 \%$ and $98 \%$. The system is regulated with a PID control programmed in LabView with a Rotronic S-type RH/T-sensor giving the aerosol RH just before DMA2 as the input signal and using the current to the Peltier element as the output signal. The RH in DMA2 is calculated by the combination of the dew point temperature, $T_{\text {dew }}$, given by a General Eastern hygro M1 dew point meter in the DMA2 loop and the average value of three Pt100-elements taped to the outer wall of DMA2 at different heights (bottom, middle and upper part of
DMA2). This way, the longitudinal temperature gradient of the DMA is measured. However, there is no measurement of a possible radial temperature gradient in the DMA body. The temperature in the DMA is assumed to be the same as on the DMA surface. Both the dew point sensor and the Pt100elements were calibrated against a temperature sensor with an accuracy of $0.03 \mathrm{~K}$. The $\mathrm{RH}$ is calculated from the empirical saturated water vapour pressure function derived by Buck (1981). This value has a higher accuracy than the Rotronic sensors, so every second hour, this RH value is used to automatically calibrate the Rotronic sensor used in the RH control. This way, the problem of long term drift on the Rotronic sensor is eliminated.

Previously, most H-TMDA systems have not been temperature controlled in a rigorous way. Often, some sort of insulation of the second DMA has been used, sometimes in combination with a crude temperature stabilisation, such as water hoses with or without temperature control, attached to the outer walls of the second DMA. However, an unstable temperature can have a substantial influence on $\mathrm{RH}$, especially close to saturation. Therefore, active temperature control of the second DMA was used, with two Peltier elements ( $\mathrm{Su}-$ percool AA-040-12-22-00-00) with an external control unit (Supercool TC-XX-PR-59), running separate from the computer with the LabView software used for controlling the rest of the H-TDMA system. The Peltier elements were fixed to the aluminium walls of the insulated box. They were delivered with two blowers mounted to each element, one on the outside of the box, and one recirculating the air inside the box. The inner dimensions of the DMA1 box were $400 \times 460 \times 950 \mathrm{~mm}$, the last one being the height. The Peltier elements $(110 \times 130 \times 80 \mathrm{~mm}$, the last one being the thickness) were mounted on the centre of the short side, with their base 360 and $690 \mathrm{~mm}$ from the floor of the box respectively. The temperature gradient inside the box was measured to be less than $0.1 \mathrm{~K}$ from one bottom corner to the diagonal opposite upper corner with DMA2 and all tubing and sensors mounted, using the same three Pt100 elements later tapered to the surface of DMA2. The temperature of DMA1 and the humidification system is kept at laboratory temperature $\left(20^{\circ} \mathrm{C}\right)$, with the same setup as previously described for DMA2, but with only one Peltier element used, since potential temperature gradients are not a problem for dry measurements. The inner dimensions of box 1 were $360 \times 460 \times 950 \mathrm{~mm}$, the last one being the height. The Peltier element was mounted with its base $600 \mathrm{~mm}$ from the floor of box 2 .

DMA1 working temperature is set two degrees lower than DMA2. In this way, less water is used (which ultimately end up in the CPC) and the risk of condensation in the closed loop, which is partly situated outside of the temperature controlled box, becomes smaller. However, this also means that the residence time after the aerosol enters the second box has to be long enough so that the aerosol reaches the new temperature. The residence time between DMA1 and DMA2 has 
been approximated to $3 \mathrm{~s}$, whereof $0.2 \mathrm{~s}$ is between the humidifier and the wall between box 1 and box 2 . A longer residence time would lessen the risk of the particles not reaching equilibrium before entering DMA2, but would on the other hand increase the particle losses, a parameter which can be of importance when conducting background measurements.

To validate the data obtained during unattended long term measurements, automatic ammonium sulphate scans are performed at $90 \% \mathrm{RH}$ (same as the RH used for the ambient measurements) every 23rd hour. This time interval was chosen to make sure that the validation measurements are not constantly performed at the same time of day. Sampling is automatically switched between ambient measurements and atomized ammonium sulphate with a two way valve. When sampling from the atomizer (TSI, model 3076), a compressor connected to the atomiser activates and starts generating the salt aerosol. The validation measurements are carried out for the same dry sizes used for ambient measurements $(35 \mathrm{~nm}$, $50 \mathrm{~nm}, 75 \mathrm{~nm}, 110 \mathrm{~nm}, 165 \mathrm{~nm}$ and $265 \mathrm{~nm}$ ).

The system was tested in the laboratory before it was transported to the field site. Measurements were performed on atomized ammonium sulphate particles with a dry diameter of $100 \mathrm{~nm}$ for RH values between $70 \%$ and $95 \%$ and compared to electrodynamic balance data from Tang and Munkelwitz (1994).

It is assumed that the particles entering DMA2 carries only one charge. Doubly charged particles will have a slightly larger GF, as they are larger than the singly charged ones, and consequently less influenced by the Kelvin effect. It is possible to correct for this, as long as size distribution measurements of the entire aerosol is simultaneously conducted, but in previous work this effect has not been taken into account, as H-TDMA measurements are usually conducted at sizes where the probability of double charging is relatively small $(<400 \mathrm{~nm})$. The effect can be significant if measurements are conducted at dry sizes below the median value of a narrow size distribution, as sometimes is the case in laboratory studies, but under normal atmospheric circumstances the effect should be small (Swietlicki et al., 2008).

The data is evaluated with the IGOR TDMAinv toolkit (Gysel et al., 2009).

\section{Results and discussion}

It was concluded that the H-TDMA was giving results very similar to the reference data for the laboratory experiments on ammonium sulphate (Fig. 2), with GF deviations from literature values between 0.14 and 0.034 and corresponding RH deviation values between $0.2 \%$ and $1.2 \%$ for $\mathrm{RH}$ values between $70 \%$ and $95 \%$. Assuming that all other hardware works perfectly, the minimal uncertainty of the measurement is defined by the accuracy and the precision of the temperature measurement of DMA2 and the dew point temperature measurement. The dew point meter accuracy is specified as

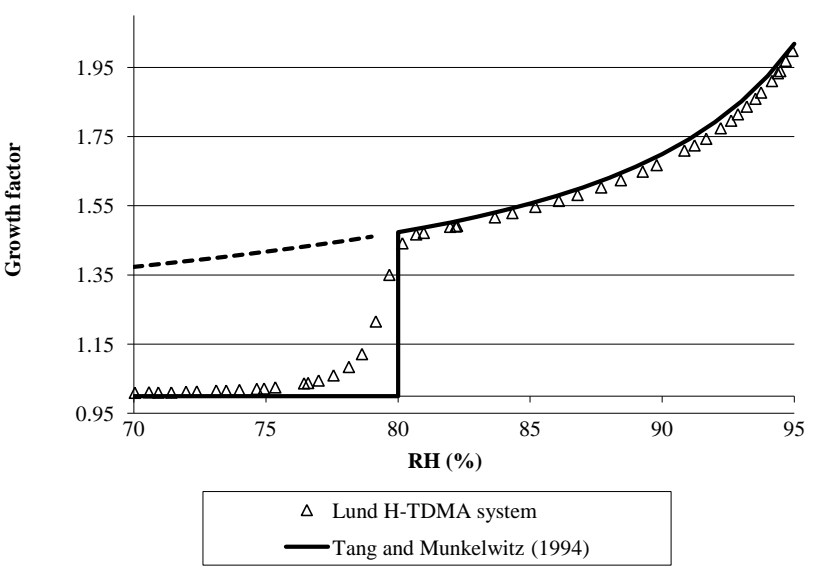

Fig. 2. Humidogram of ammonium sulphate for $100 \mathrm{~nm}$ particles. The solid and the dashed lines represents electrodynamic balance data from Tang and Munkelwitz (1994). The solid line describes the deliquescence water uptake at increasing $\mathrm{RH}$ and the dashed line shows the hysteresis effect when the aerosol has been prehumidified to an $\mathrm{RH}$ above the deliquescence point, and thereafter dried to a given $\mathrm{RH}$.

$0.1 \mathrm{~K}$ from the manufacturer. The Pt100 element precision is unspecified although measurements have suggested a precision around $0.05 \mathrm{~K}$. From the equation derived by Buck (1981), a worst case scenario based on temperature uncertainty can be calculated. For a DMA2 temperature of around $20^{\circ} \mathrm{C}$ this gives an RH error of $\sim \pm 0.8 \%$. Considering uncertainties in flows, voltages, charging efficiency, purity of the reference solution etc. the deviations from theory can be expected to be higher than that, and this can be seen in Fig. 5, where a few outliers are visible, most likely due to one or several of the reasons previously mentioned. However, as most scans are within $\pm 1 \%$ in $\mathrm{RH}$ compared to the expected values, it can be concluded that the measurement uncertainty for these salt scans are dominated by the limited precision in the temperature measurements, as previously discussed. These results also support the assumption that the radial temperature gradients are negligible, since a radial temperature gradient of $0.2 \mathrm{~K}$ would give a shift of $\sim 1 \%$ in RH. At an RH of $79.9 \%$, the ammonium sulphate crystals take up water and rapidly form a saturated solution. The deliquescence RH (DRH) of the salt is somewhat smeared in the DRH measurement (Fig. 2). This is not expected for a pure solution, but the effect has been seen before, especially for small particles (e.g. Hämeri and Väkevä, 2000) and can possible be attributed to a contamination of the salt solution. This would be consistent with theory, as it has been shown that a mixture of ammonium sulphate and an organic acid can smear the deliquescence point (Russell and Ming, 2002). It is also possible that it is a consequence of temperature gradients in the DMA, deliquescing the particles somewhere inside the DMA. However, given the relatively low RH at which this phenomenon 


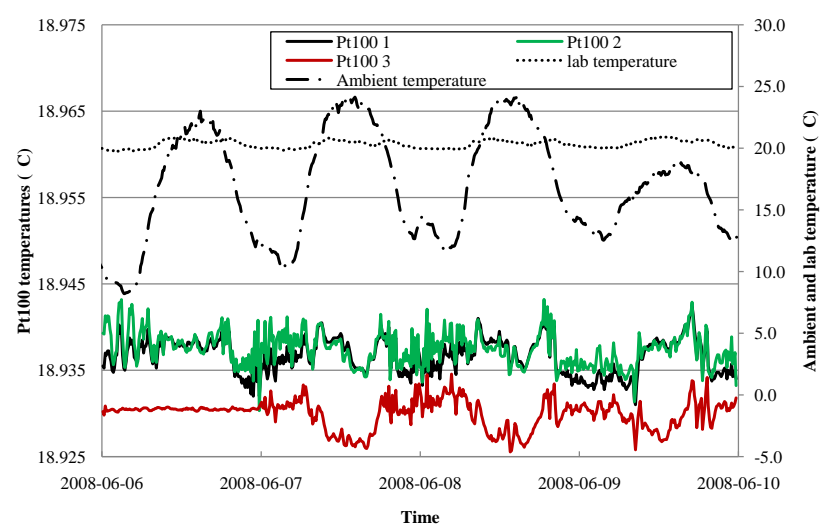

Fig. 3. Example of temperature stability of DMA2 at the remote field site Vavihill. Three Pt100 sensors are placed on different places on the DMA, one sensor monitors the ambient temperature, and one sensor is placed inside the lab. The Pt100 sensors correspond to the left side axis and the laboratory and the outside temperature correspond to the right side axis.

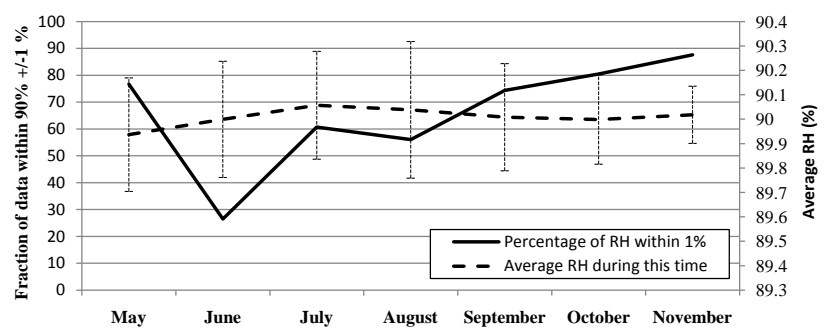

Fig. 4. RH stability of DMA2 in field. The RH average values are taken from data that are within $1 \%$ of the setpoint of $90 \% \mathrm{RH}$. The error bars represent standard deviations of the $\mathrm{RH}$ values during these times. For November, data until the 14th is included.

occurs $(\sim 77 \%)$ it is unlikely that this alone is the reason, especially considering that the measured temperature gradient of the DMA is less than $0.1 \mathrm{~K}$ (see Fig. 3). Another possibility would be that the particles deliquesce near the walls of the Gore-Tex ${ }^{\circledR}$ tube, though this effect would show a bimodal distribution in the second DMA, and this was not the case. In any case, since this instrument is not intended for laboratory measurements of chemically pure compounds, it was concluded that the results were satisfactory.

The H-TDMA has been running continuously since May 2008 until January 2009 at the EMEP/EUSAAR field station Vavihill $\left(56^{\circ} 01^{\prime} \mathrm{N}, 13^{\circ} 09^{\prime} \mathrm{E}, 172 \mathrm{~m}\right.$ a.s.l.). The stability showed in the laboratory was proven somewhat lower in the field, but still well within desired performance criteria. The longitudinal temperature gradient in the second DMA, measured at three points on the DMA body (lower, middle and upper part), was in the field measured to less than $0.06 \mathrm{~K}$ (see Fig. 3) during 4 days of operation, even though outside temperature had a diurnal variation of $\sim 15 \mathrm{~K}$. The $\mathrm{RH}$ of the

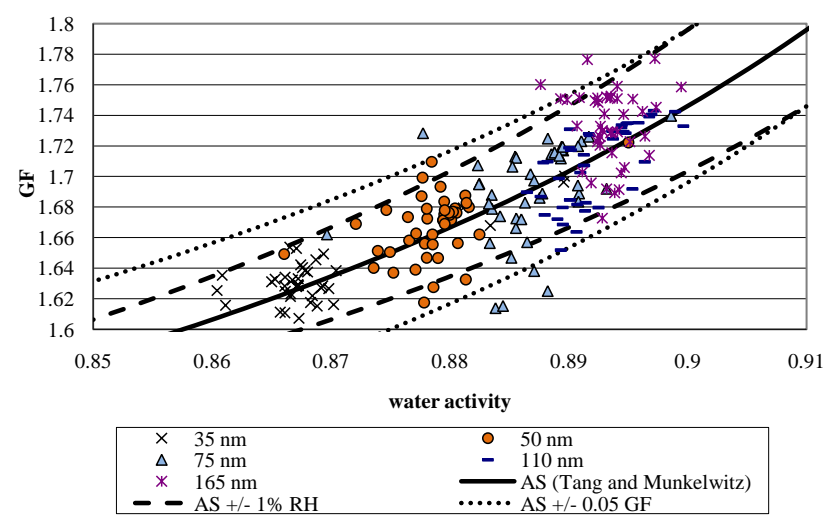

Fig. 5. Automatic ammonium sulphate scans from August and September. All measurements are carried out with an RH setpoint of $90 \% \mathrm{RH}$. Due to the Kelvin effect, the water activity and hence the GF varies with dry size. This is clearly visible and almost all scans are within $\pm 1 \% \mathrm{RH}$ and $\pm 0.05 \mathrm{GF}$. The dotted lines represent deviations from the Tang and Munkelwitz values with $\pm 1 \% \mathrm{RH}$ and \pm 0.05 GF respectively.

system was also very stable, with monthly average values of $90 \% \pm 0.07 \%$ and standard deviation (STD) values less than $0.28 \%$ for all months. Figure 4 shows the RH data for which dew point measurements fall within $1 \%$ of the desired value of $90 \% \mathrm{RH}$, and the corresponding fraction of time when this criteria was filled for each month. The majority of the ammonium sulphate measurements fall within the desired criteria of \pm 0.05 in GF, although some outliers exist. The Kelvin effect, giving rise to the smaller growth factor of smaller particles is clearly visible, as lower water activities correspond to lower growth factors (Fig. 5).

The system had a number of malfunctions causing data gaps during its first months of operation, mostly due to problems with the linear pump, power failures at the field site and errors in the Labview control system code. However as problems are addressed the fraction of data covered time increases and was over $90 \%$ for the last three months of operation recorded in this work. The limiting factor for maintenance is that the water used in the humidification ultimately ends up in the CPC, which gradually lowers its performance, until finally the number of counted particles is virtually zero. In a typical case, the instrument can operate around 2 weeks, before the CPC has to be drained on water and filled with new butanol working fluid to prevent too low counting statistics. This problem could be corrected using a water based CPC instead of a butanol based. Since the CPC is operating well beyond its cutoff size, which is around $10 \mathrm{~nm}$, the choice of working fluid should not affect the results of this particular instrument. Another drawback is that the instrument is not able to recover from a power cut. This is due to the software used for the temperature control of the two DMA boxes, which has not been LabView implemented, but is run through a separate problem. However, if that serial 
Table 1. Average and standard deviation of the growth factor and the water activity values from the automated ammonium sulphate scans.

\begin{tabular}{ccccc}
\hline Dry size & GF (average) & GF STD & $a_{w}$ (average) & $a_{w}$ STD \\
\hline $35 \mathrm{~nm}$ & 1.6237081 & 0.02234 & 0.8662094 & 0.00521 \\
$50 \mathrm{~nm}$ & 1.6658702 & 0.01964 & 0.8781546 & 0.00299 \\
$75 \mathrm{~nm}$ & 1.69231976 & 0.02989 & 0.8867795 & 0.00446 \\
$110 \mathrm{~nm}$ & 1.70843828 & 0.0256 & 0.8922586 & 0.00327 \\
$165 \mathrm{~nm}$ & 1.73254144 & 0.02419 & 0.8934233 & 0.00223 \\
\hline
\end{tabular}

communication were to be run through LabView, and a computer with automatic booting upon power return, there is no theoretical reason to why an automatic restart of the system after power failures should not be possible.

\section{Conclusions}

An H-TDMA designed for long term measurements of the ambient aerosol was constructed within the FP6 Infrastructure Project EUSAAR, according to recommendations resulting from intercomparison workshops and discussions within the project. It was concluded that the field growth factor precision of the H-TDMA was \pm 0.05 with respect to ammonium sulfate calibration measurements which corresponds to $\pm 1 \%$ in $\mathrm{RH}$ precision. The system has been found very stable, with a standard deviation value of less than $0.3 \% \mathrm{RH}$ from the $90 \% \mathrm{RH}$ set point. This stability is partially attributed to the simple and robust Gore-Tex ${ }^{\circledR}$-water humidification system, only humidifying the aerosol, and using the second DMA and its loop as a buffer for fluctuations in the humidification system, and partially attributed to the temperature stability of the system, which is a pre-requisite for producing high quality data during unattended operation. Although a number of malfunctions have caused gaps in the data, the stability of the system was improved by modifications of the H-TDMA and replacement of low performing parts. It can be concluded that the design recommendations given by EUSAAR are sufficient for conducting high quality long term measurements of the hygroscopic properties of the ambient aerosol.

This work was carried out within the frameworks of the EU FP6 Integrated Project EUCAARI, the EU FP6 Infrastructure Project EUSAAR as well as the NOS-N Nordic Centre of Excellence BACCI.

Edited by: A. Wiedensohler

\section{References}

Buck, A. L.: New Equations for Computing Vapor Pressure and Enhancement Factor, J. Appl. Meteorol., 20, 1527-1532, 1981.
Ehn, M., Petäjä, T., Aufmhoff, H., Aalto, P., Hämeri, K., Arnold, F., Laaksonen, A., and Kulmala, M.: Hygroscopic properties of ultrafine aerosol particles in the boreal forest: diurnal variation, solubility and the influence of sulfuric acid, Atmos. Chem. Phys., 7, 211-222, 2007, http://www.atmos-chem-phys.net/7/211/2007/.

Duplissy, J., Gysel, M., Sjogren, S., Meyer, N., Good, N., Kammermann, L., Michaud, V., Weigel, R., Martins dos Santos, S., Gruening, C., Villani, P., Laj, P., Sellegri, K., Metzger, A., McFiggans, G. B., Wehrle, G., Richter, R., Dommen, J., Ristovski, Z., Baltensperger, U., and Weingartner, E.: Intercomparison study of six HTDMAs: results and general recommendations for HTDMA operation, Atmos. Meas. Tech. Discuss., 1, 127168,2008 ,

http://www.atmos-meas-tech-discuss.net/1/127/2008/.

Gysel, M., McFiggans, G. B., and Coe, H.: Inversion of tandem differential mobility analyser (TDMA) measurements, J. Aerosol Sci., 40, 134-151, 2009.

Hennig, T., Massling, A., Brechtel, F., and Wiedensohler, A.: A tandem DMA for highly temperature-stabilized hygroscopic particle growth measurements between $90 \%$ and $98 \%$ relative humidity, J. Aerosol Sci., 36, 1210-1223, 2005.

Hämeri, K. and Väkevä, M.: Hygroscopic growth of ultrafine ammonium sulphate aerosol measured using an ultrafine tandem differential mobility analyzer, J. Geophys. Res., 105(D17), 2223122242, 2000.

Kaufman, Y. J., Tanre, D., and Boucher, O.: A satellite view of aerosols in the climate system, Nature, 419, 215-223, 2002.

Liu, B. Y. H., Pui, D. Y. H., Whitby, K. T., Kittelson, D. B., Kousaka, Y., and McKenzie, R. L.: The aerosol mobility Chromatograph: A new detector for sulfuric acid aerosols, Atmos. Environ., 12, 99-104, 1978.

Massling, A., Stock, M., and Wiedensohler, A.: Diurnal, weekly, and seasonal variation of hygroscopic properties of submicrometer urban aerosol particles, Atmos. Environ., 39, 3911-3922, 2005.

Russell, L. M. and Ming, Y.: Deliquescence of Small Particles, J. Chem. Phys., 116, 311-321, 2002.

Santarpia, J. L., Li, R., and Collins, D.: Direct measurement of the hydration state of ambient aerosol populations, J. Geophys. Res., 109, D18209, doi:10.1029/2004JD004653, 2004.

Swietlicki, E., Hansson, H.-C., Hämeri, K., Massling, A., Petäjä, T., Tunved, P., Weingartner, E., Baltensperger, U., McMurry, P.H., McFiggans, G., Svenningsson, B., Rissler, J., Wiedensohler, A., and Kulmala, M.: Hygroscopic Properties of Sub-Micrometer Atmospheric Aerosol Particles Measured with H-TDMA Instruments in Various Environments - A Review, Tellus B, 60, 3, 353364, 2007.

Tang, I. N. and Munkelwitz, H. R.: Water activities, densities, and refractive indices of aqueous sulphates and sodium nitrate droplets of atmospheric importance, J. Geophys. Res., 99(D9), 18801-18808, 1994.

Weingartner, E., Nyeki, S., and Baltensperger, U.: Hygroscopic properties of aerosol particles at low temperatures $\left(\mathrm{T}<0^{\circ} \mathrm{C}\right), \mathrm{J}$. Aerosol Sci., 30, S17-S18, 1999.

Zhou, J.: Hygroscopic properties of atmospheric aerosol particles in various environments, ISBN 91-7874-120-3, Doctoral dissertation at Lund University, Dep. of Nuclear physics, Lund, Sweden, 2001. 